\title{
How Might Degrees of Belief Shift? On Action Conflicting With Professed Beliefs
}

Darrell P. Rowbottom

DarrellRowbottom@ln.edu.hk

\begin{abstract}
People often act in ways that appear incompatible with their sincere assertions (such as trembling in fear when their death becomes an imminent possibility, despite earlier professing that "Death is not bad!"). But how might we explain such cases? On the shifting view, subjects' degrees of belief (or degrees of confidence) may be highly sensitive to changes in context. This paper articulates and refines this view, after defending it against recent criticisms. It details two mechanisms by which degrees of beliefs may shift.
\end{abstract}

\section{Action Contrary to Professed Beliefs}

Let's begin by considering a puzzling situation:

Kaipeng the trembling Stoic. Having been won over by the Stoics ... Kaipeng quite sincerely judges, not just on one occasion but repeatedly, that death is not bad. He can recite arguments toward the conclusion, arguments he finds compelling and which he fully accepts as he makes them. Yet he trembles on the battlefield, and not just in anticipation of pain. He regrets the death of a good person, and not entirely on behalf of those who have lost the benefit of her company. He takes measures to forestall his own death, and not wholly 
from a sense of duty. His actions and reactions for the most part are indistinguishable from the actions and reactions of someone who considers death bad ... Kaipeng could be perfectly well aware of these facts about himself and seek to change them - perhaps through meditative practices - yet they remain mostly unchanged. (Schwitzgebel 2010: 537-538)

Similar situations are common, and there are philosophical examples to boot. For example, a scientific anti-realist may find herself behaving as if scientific theories are true, when confronted by a medical emergency. But this need not alter her philosophical position. And perhaps it should not. Why? When philosophizing, our anti-realist may be concerned with epistemic issues only. But when she goes about her daily life, prudential concerns become relevant. Similarly, when sat safely in his barracks, pondering the state of the philosophical debate on Stoicism, Kaipeng may be concerned purely with epistemic matters. When faced with his potential death on the battlefield, however, he may be concerned with rather more. The penalty for being wrong about death being bad, in that context, is all too clear. So he might (implicitly, if not explicitly) then take his epistemic reasons to be insufficient to deny that death is bad. His degree of belief in that proposition may change as a result.

The above is a very first pass at motivating the 'shifting' response to the scenario, which I develop in this paper. But three initial remarks should be borne in mind. First, such a scenario might have more than one reasonable possible explanation. And I do not wish to argue that shifting is the only such explanation, rather than one such explanation. Second, nothing hinges on thinking that such shifting is potentially, let alone always, rational. Evidentialists and their opponents may disagree on this, while 
accepting the shifting account. Third, shifting may occur in more than one way. Only one possible form of shifting is suggested above. It may fail to occur while another form of shifting does occur.

The bulk of this paper is devoted to explicating and developing the shifting view. But I should like to begin by addressing the existing criticisms of the view. This is slightly awkward, unfortunately, because the position is not given a serious treatment by most authors who mention it. Borgoni (2014: n.3), for instance, simply asserts: 'the view has obvious flaws. For example, it is unable to describe cases in which Juliet argues for racial equality while engaging in racist behavior.' One might wonder, however, whether the alleged flaws are so 'obvious' when they are given such short shrift. In any event, we will shortly see that the shifting view can be used to provide a satisfactory description of the Juliet case, which is as follows.

Juliet is a Caucasian academic who argues sincerely that all races are equal in professional contexts (e.g., her articles) but is implicitly racist in many of her actions. For example, she feels much more surprised when black students write excellent essays than she does when non-black students do. She becomes upset when entertaining the possibility that her daughter is dating a black man. And so on.

Schwitzgebel (2010) criticizes the shifting view on the basis of this case; and Borgoni (2014) refers only to his critique. To set this up, let's accept Schwitzgebel's (2002: 262) view that beliefs are purely dispositional in character: 'Once all the relevant dispositions have been made clear, the case is closed. There are no further facts to report.' And let's also accept Schwitzgebel's (2002: 253) specific definition of belief: 
'To believe that $\mathrm{P} \ldots$ is nothing more than to match to an appropriate degree and in appropriate respects the dispositional stereotype for believing that P.' But note that one need not accept either of these claims in order to defend a shifting view, as we will later see. The ground is given, here, partly in order to illustrate that the shifting view survives even when much is conceded to this critic. (It's given partly to streamline the discussion.)

The stage is set. Here are the two arguments against the 'shifting view':

The main problem with this approach is that it leaves us without resources to describe the subject's overall attitude. When Juliet is mowing the lawn, with general propositions about equality far from her mind, and neither seeing nor thinking about anyone of any skin color, what does she believe - that the races are intellectually equal or that they're not? The shifting approach leaves us stymied. It doesn't seem right to say she has no belief about the races at such a moment: Beliefs are dispositional; one doesn't cease believing when one falls asleep or turns one's mind to another topic; we don't need to find out what someone is currently doing to say what she believes the way we need to find out what someone is currently doing to say whether she is jogging. We need to be able to speak about Juliet globally, not just about her shifting judgments or assumptions in particular individual conditions. What's her general attitude? Furthermore, it seems possible for Juliet in a single moment both to be having a racist reaction and to be sincerely judging that the races are intellectually equal - for example, when she's having a racist reaction and trying to suppress it or when she's grading a black student's essay on intellectual equality, 
undervaluing the essay but regarding its conclusions as true. This is a possibility the shifting model gives us no means to accommodate. (Schwitzgebel 2010: 543)

The first (and 'main') line of argument, which asks 'What's her global attitude?', fails because it misrepresents the shifting view. The shifting view is not that one's dispositional profile always shifts when one changes situation or context. (Recall, I will grant in what follows - although do not wish to accept, and need not presume that Schwitzgebel's dispositionalism about belief is correct.) It is just that it may shift in the situations under discussion, in such a way as to explain the behaviour. So when Juliet is mowing the lawn, there may be a straightforward fact of the matter about the value of her degrees of belief concerning racial equality. And that fact of the matter need not change when she is instead washing the dishes, sunbathing on a Pacific island, or sleeping peacefully. Change may occur only with specific triggers, such as actual or imagined encounters with non-Caucasian persons. Hence, we may speak of Juliet's belief(s) in more than 'particular individual conditions'. Moreover, the claim that we 'need to' be able to talk of a 'global attitude' is false. The scope of our belief attributions is always implicitly limited. We presuppose that beliefs are sensitive to some changes in context (involving, e.g., severe brain damage or reading a good philosophy book in an open-minded way). Furthermore, we often have no trouble in anticipating how they are likely to change on a scenario-by-scenario basis. Hence, the 'local' versus 'global' issue is a false dilemma. We want to be able to talk about Juliet only in some significant class of scenarios where her (relevant) dispositions won't change when we ascribe beliefs (or degrees thereof) to her. And we can do that on the shifting view. 
Note also that even if Juliet's degrees of belief in said propositions are difficult to measure on some occasions - e.g., during lawn mowing - this is a weak argument that they do not exist. Perhaps the available ways of trying to measure them serve to disturb them. Think of position measurements on Bohm's interpretation of quantum mechanics, by way of comparison. ${ }^{1}$ Particles always have definite positions, but must be disturbed during measurement, such that said positions subsequently become uncertain to the experimenter. Nevertheless, one can delimit the possibilities concerning the position by measurement, and the same may be true, by analogy, with respect to degrees of belief. Indeed, dispositional profiles (and hence 'general attitudes' on Schwitzgebel's view) are also extremely hard to measure, rather than guess at; we typically only have the opportunity to measure a small part of these, even assuming that they exist. But Schwitzgebel nonetheless believes in dispositional profiles, and that we can say useful things about them in individual cases.

The second line of argument - from the 'single moment' involving conflicting manifestations - only targets particular cases, involving what might be called 'synchronic mismatches'. Hence, it doesn't rule out the shifting view for diachronic mismatches. Moreover, the existence of synchronic mismatches is dubious. Partly, this is because degrees of belief are not luminous. That's to say, one may be mistaken about what one's degrees of belief are. This is an old argument, due to Ramsey, which we will cover in the next section. It's significant because Juliet may be 'sincerely judging that the races are intellectually equal', in the precise sense that it seems to her that she thinks it's true, although her own degree of belief in the proposition may be

\footnotetext{
${ }^{1}$ For an accessible introduction to Bohm's interpretation, see Cushing (1994).
} 
below the threshold for belief, or simply be low enough to explain some racist behaviour on her part (in combination with her other propositional attitudes, etc.).

But now imagine this is wrong. Imagine degrees of belief are luminous. Why might rapid fluctuations not be occurring in the Juliet case? Even in physics, we cannot measure what is happening in a moment. We estimate instantaneous velocities, for example, by measuring average velocities. We can only measure distance travelled over some finite time interval. Similarly, it is extremely difficult to tell the difference, empirically, between fast shifting occurring and some other phenomenon (like an odd dispositional profile) being present. We do not experience moments qua time slices. Moreover, it is implausible that we are typically aware of precisely how and when our beliefs (or degrees thereof) change, on the basis of introspection. ${ }^{2}$

The idea that our dispositional profiles (or degrees of belief) sometimes fluctuate like this might seem counterintuitive. ${ }^{3}$ (I suspect this is partly because we imagine ourselves to be more rational, and stable, than we are; I will return to this in section

\footnotetext{
${ }^{2}$ Indeed, Schwitzgebel (2008) argues that introspection is untrustworthy even when it concerns our own conscious experience. Schwitzgebel (2011) also expresses pessimism about one's ability to detect whether one is in a state of in-between believing (at least in a specific type of case), even assuming such states exist.

${ }^{3}$ However, in an early (2005) draft of Schwitzgebel (2010), available on Schwitzgebel's website (http://www.faculty.ucr.edu/ eschwitz/SchwitzAbs/ActBel.htm), the possibility of rapidly shifting dispositions is explicitly admitted: 'Dispositions can be fleeting, can come and go. Twigs are fragile when frozen. Francie is prone to snap at her husband when drinking her morning coffee...' The relevant discussion appears in section five of the draft. This was condensed into footnote nine of Schwitzgebel (2010).
} 
three.) But it would be a serious mistake to dismiss the possibility of fluctuations just because it seems 'unnatural'. The history of science offers numerous examples of cases where the counterintuitive view ended up becoming the orthodox one; consider, for example, non-locality in quantum theory and time dilation in relativity theory. The history of science also offers numerous examples of theoretical corrections or innovations that appeared ad hoc initially, but were subsequently accepted. The positing of neutrinos - to save the laws of conversation of energy and momentum - is just one such case.

In summary, the response to the second line of argument, based on synchronic mismatches, is as follows. Although there's no conceptual barrier to their existence, it's difficult to tell if they exist. And even if it's granted that they exist, it's extremely hard to tell how frequently they occur. So at best, this objection shows that the shifting view isn't true in general for the kind of mismatch scenarios we've discussed. But I grant this point, as I mentioned at the beginning of the paper.

I am not even arguing for the bold conclusion that shifting probably occurs in the Juliet scenario (or indeed the Kaipeng scenario). I am arguing, rather, that it is a salient possibility that shifting occurs, given the narrative/description. ${ }^{4}$ Of course, it is possible to alter that narrative, such that no shifting occurs. For example, one might specify that Juliet's dispositional profile remains identical throughout the process. But this would be to rule out the shifting view by fiat. This would be inappropriate

\footnotetext{
${ }^{4}$ Being a salient possibility entails having a reasonably high probability in comparison with the available rivals. However, this is even compatible with having the lowest probability of the available hypotheses.
} 
because the interesting cases we're trying to explain - and are canvassing possible explanations for - are like the Juliet case as described (i.e., cases where it's unclear that the dispositional profile remains identical, precisely because of the difficulties in measuring such a profile, even assuming said profile exists in a metaphysically robust sense).

It would be lazy to assume that all such cases are explicable in the same way (when explanation is assumed to be factive). Some real life Kaipeng-type or Juliet-style cases may have shifting explanations, and others may not. At no point in this paper shall I assume otherwise. Part of the difficulty is precisely the similar empirical consequences of the different accounts. I framed the discussion above in terms of Schwitzgebel's account because he is the only author who attempts to argue against the shifting view. (Assuming dispositionalism enabled me to quote him directly, and to illustrate the compatibility of the shifting view with this thesis.) But Schwitzgebel's 'in-between believing' perspective is not the only alternative, let alone the only viable alternative, to the shifting view. Consider also: 'the pro-judgment view, on which the subject... believes that P and fails to believe not-P [Zimmerman 2007; Gendler 2008a $\&$ 2008b]; the anti-judgment view, on which the subject fails to believe that $\mathrm{P}$ and instead believes not-P [attributed to David A. Hunter in an unpublished paper] ... and the contradictory belief view, on which the subject believes both P and not-P [Gertler 2011 and Borgoni 2014].' (Schwitzgebel 2010: 537). I do not wish to dismiss any of these views. On the contrary, I believe we should entertain the possibility that each of these is true for some cases. It seems eminently plausible, at the bare minimum, that the pro-judgment and anti-judgment explanations are correct in some situations where there's a conflict between professed beliefs and actions. The descriptions/narratives - 
concerning Kaipeng and Juliet, as well as others we'll later encounter - are sufficiently coarse grained.

In this section, we have seen that the available objections to the shifting view are too quick (even when it is only roughly articulated). Here's an overview of the remainder of the paper. In the next section, I tackle two misconceptions concerning degrees of belief. I show in detail that they need not be construed as: (a) representational rather than dispositional in character; or (b) luminous. In section three, which is the most important part of the paper, I develop the shifting view. I explain that there are two key ways in which degrees of belief can shift, and illustrate these with further discussion of the hypothetical cases of mismatches between assertions and actions presented in the literature. I conclude by summarizing my key findings.

\section{Two Misconceptions About Degrees of Belief}

Before I elaborate the shifting view - and more specifically, the different means by which shifting of degrees of belief may occur - I will address two potential misunderstandings of degrees of belief. Dealing with these now will streamline the subsequent discussion.

Degrees of Belief Do Not Preclude Dispositionalism

One important misconception, which is suggested by the occasional grouping of 'representational or Bayesian' in Schwitzgebel (2001), is that degrees of belief are (or presuppose the existence of) mental representations, like beliefs according to Fodor 
(1975) and Cummins (1996). At the very least, some have suggested that there is a tension between saying that we have regularly shifting degrees of belief and adopting a dispositional view of belief. Hutto (2013), for example, writes that 'the shifting view... is hard to square with the general conviction that beliefs are dispositional states of mind' in his brief dismissal of the position. And this leads one to suspect that degrees of belief are being construed in a non-dispositional fashion.

But this is a matter on which there is no standard line in philosophy of probability or formal epistemology. In fact, there is a longstanding debate concerning the nature of degrees of belief (among philosophers of probability), which mirrors that concerning the nature of beliefs (among philosophers of mind). It began in the first half of the twentieth century, and continues to this day.

For a flavour of this debate, consider the views of Ramsey (1926) and De Finetti (1937). Each has operationalist sympathies, and thinks that degrees of belief should be defined in a way that makes them amenable to measurement. ${ }^{5}$ Hence, each relies on betting scenarios, and particularly the odds (or betting quotients) accepted therein,

\footnotetext{
${ }^{5}$ In the words of Ramsey (1926: 166-167): 'It is a common view that belief and other psychological variables are not measurable, and if this is true our inquiry will be vain; and so will the whole theory of probability conceived as a logic of partial belief ... the degree of a belief is just like a time interval; it has no precise meaning unless we specify more exactly how it is to be measured. But for many purposes we can assume that the alternative ways of measuring it lead to the same result, although this is only approximately true.' In the words of De Finetti (1990: 76): 'In order to give an effective meaning to a notion ... an operational definition is required $\ldots$ a definition based on a criterion which allows us to measure it.'
} 
in cashing out his particular variant of the subjective view of probability. Nevertheless, considerable differences are present in how each treats of degrees of belief. De Finetti, for example, adopts a behaviourist line; your degree of belief in $p$ is the betting quotient on $p$ you accept as fair, or, at any rate, have a disposition to accept as fair (in a suitable betting scenario). So in essence, degrees of belief are understood to correspond to a narrow class of dispositions. ${ }^{6}$

If Ramsey (1926: 183) is correct that 'all our lives we are in a sense betting', however, then De Finetti's account is impoverished because it focuses on a small subset of our (hypothetical or actual) actions. Instead, it seems natural to allow that degrees of belief correspond to a broader range of dispositions (or more carefully, since attitudes other than beliefs are relevant too, have a broader impact on individual dispositional profiles). Hence Ramsey (1926: 169) instead suggests that: 'the degree of a belief is a causal property of it, which we can express vaguely as the extent to which we are prepared to act on it."7

Much more could be said on this topic; it is the subject of Erikkson and Hájek (2007), which nicely illustrates how the correct ontology of degrees of belief is 'up for grabs',

\footnotetext{
${ }^{6}$ However, De Finetti sometimes writes in such a way as to contradict this view (which is defended in his early work, at least). Consider the following passage: 'The criterion, the operative part of the definition which enables us to measure it, consists in this case of testing, through the decisions of an individual (which are observable), his opinions (previsions, probabilities), which are not directly observable.' (De Finetti 1990: 76)

${ }^{7}$ Consider also: 'Having any definite degree of belief implies a certain measure of consistency, namely willingness to bet on a given proposition at the same odds for any stake, the stakes being measured in terms of ultimate values.' Ramsey (1926: 182-183)
} 
and is also discussed in Rowbottom (2015b: ch. 4). But this brief consideration of the work of De Finetti and Ramsey, the architects of the subjective interpretation of probability, indicates that degrees of belief may be construed as dispositional in character.

Equally, degrees of belief need not be construed as dispositional in character, and this is to the potential advantage of the shifting perspective in comparison to some alternative views. I won't argue for this thesis here, because it is already, as I noted earlier, widely accepted.

\section{Degrees of Belief Need Not Be Luminous}

Another possible misconception is that degrees of belief are supposed to be luminous, i.e., (typically) possible to determine by introspection. The importance of this, in the present context, may be illustrated by considering the Juliet case again. For example, I suggested that Juliet's degrees of belief might sometimes fluctuate rapidly. But this would be less plausible, on an argument from analogy concerning our own experiences, if feelings were closely correlated with having degrees of confidence (and/or having these change). That's because we'd expect her to experience the changes (and for ourselves to experience similar changes).

However, we can look again to Ramsey, who argues rather convincingly that such feelings do not exist. The following passage is especially interesting: 
[W] hen we seek to know what is the difference between believing more firmly and believing less firmly, we can no longer regard it as consisting in having more or less of certain observable feelings; at least I personally cannot recognize any such feelings. The difference seems to me to lie in how far we should act on these beliefs: this may depend on the degree of some feeling or feelings, but I do not know exactly what feelings and I do not see that it is indispensable that we should know ... It will no doubt be objected that we know how strongly we believe things, and that we can only know this if we can measure our belief by introspection. This does not seem to me necessarily true; in many cases, I think, our judgment about the strength of our belief is really about how we should act in hypothetical circumstances ... It is possible that what determines how we should act determines us also directly or indirectly to have a correct opinion as to how we should act, without its ever coming into consciousness. (Ramsey 1926: 170-171)

So on Ramsey's account, Juliet might have the resources to work out how strongly she believes in racial equality by thinking about how she'd react in relevant situations, e.g. those where it would be possible for her to discriminate against those of different races. Naturally, however, such judgements are fallible. And it is not unusual for people to imagine they are disposed to behave in ways that they would like to behave; e.g., that they would intervene in order to prevent a violent crime in progress in a public place, although studies on the so-called 'bystander effect' indicate that this is highly unusual. ${ }^{8}$ In essence, then, it is plausible, on Ramsey's view of how we assess

\footnotetext{
${ }^{8}$ Other examples abound, and the classic work of Festinger, Milgram and Zimbardo, in particular, springs to mind. But I will not rehearse all this here.
} 
our degrees of belief, that subjects will be especially bad at determining a proper subset of these (unless, perhaps, they are appropriately well-informed about the relevant studies in experimental psychology).

\section{Forms of Shifting: Two Mechanisms}

What does it mean to say that a subject's degree of belief in (or degree of confidence about) a proposition shifts? A clear answer to this question is crucial, if we are to appreciate the prospects of the shifting view for explaining the cases of Kaipeng and Juliet (among others). And a formal approach helps considerably in achieving such an answer.

As a precursor, consider that all degrees of belief are fundamentally conditional in character, in so far as a subject's degree of belief in $p$ is dependent on her other beliefs. ${ }^{9}$ Keynes (1921: 6-7), who believed that rational degrees of belief should match probabilities qua logical relations between propositions, put it as follows:

No proposition is in itself either probable or improbable, just as no place can be intrinsically distant; and the probability of the same statement varies with the evidence presented, which is, as it were, its origin of reference. It is as useless... to say " $b$ is probable" as it would be to say " $b$ is equal," or " $b$ is greater than," ...

\footnotetext{
${ }^{9}$ In fact, her degree of belief in $p$ will be dependent on her other degrees of belief. But for present purposes, and for simplicity's sake, we will avoid using any formal representations that allow for this.
} 
Substituting 'believable' and 'unbelievable' for 'probable' and 'improbable', and 'believability' for 'probability', makes this evident. Or one may instead look to De Finetti (1900: 194), who identified probabilities with rational degrees of belief, and argued that:

[E]very prevision, and, in particular, every evaluation of probability, is conditional; not only on the mentality or psychology of the individual involved, at the time in question, but also, and especially, on the state of information in which he finds himself at that moment. [Emphasis mine]

A simple example serves to illustrate the point. As I type, I am highly confident that Earth will not be destroyed in the next decade. But if I were shortly to see on the news that a moon-sized asteroid is set to collide with Earth in the next year - it is not April 1 ! - then my confidence in Earth's survival past ten years would drop sharply. That something similar holds for all one's beliefs is only dubious in so far as basic perceptual beliefs, such as 'I am now experiencing pain', are concerned. But we need not worry about these, since the examples with which we are concerned - e.g., the Kaipeng and Juliet cases - do not concern beliefs of this sort.

So we should consider conditional degrees of belief, which we can represent in a similar way to conditional probabilities. (It may be a necessary condition for S's degrees of belief to satisfy the axioms of probability in order for S to be rational. But the advocate of the shifting view need not assume that all degrees of belief, let alone all shifts thereof, are rational. Hence, using subjective probabilities would be inappropriate.) Let $\mathrm{D}_{\mathrm{S}}(p \mid b)$ represent how confident a subject $\mathrm{S}$ is about $p$, assuming 
$b$ is true. We may say that $\mathrm{D}_{\mathrm{S}}(p \mid b)$ is active for $\mathrm{S}$, at time $t$, when $b$ represents $\mathrm{S}$ 's background information at $t$. But $\mathrm{S}$ may also have a value for $\mathrm{D}_{\mathrm{S}}(p \mid b)$ when it is inactive, and $b$ represents only potential background information. If this is still unclear, consider again the previous example. Let $p$ be 'Earth will be destroyed within ten years', and $b$ be my current background information plus 'A moon-sized asteroid is set to collide with Earth in the next year'. There is a fact of the matter about the value of $\mathrm{D}_{\text {Author }}(p \mid b)$, although it is inactive at present. ${ }^{10}$

Note also, with respect to the earlier discussion of dispositions, that $\mathrm{D}_{\mathrm{S}}(p \mid b)$ may be described precisely as the degree of belief that $\mathrm{S}$ is disposed to have in $p$ when $\mathrm{S}$ assumes (or has the background information set) $b .{ }^{11}$

The stage is now set for us to consider the two ways in which degrees of belief may be said to shift, or to change over time. In doing so, we will see in greater detail how several of the scenarios described by Schwitzgebel - where professed beliefs are apparently incompatible with actions - may be explained in terms of (rational or irrational) shifting.

Before I continue, however, I'd like to emphasize that shifting often affects multiple degrees of belief simultaneously, when it occurs. For example, learning that a moon-

\footnotetext{
${ }^{10}$ One might doubt whether the value is sharp. But it's possible to understand the degree of belief as a well-defined interval, such as [0.1, 0.05]. See, for example, Joyce (2010) and Chandler (2014).

11 These are therefore a subset of dispositions to (degree of) believe. On the difference between dispositional beliefs and dispositions to believe, see Audi (1994). For more on how we might understand 'background information', or 'background knowledge', see Williamson (2015).
} 
sized asteroid is going to hit the Earth in the next year would affect my active degree of belief that I should send my daughter to school, that I should continue to work, that spending on the space program should be increased, that I shouldn't smoke cigarettes, and so forth. Nevertheless, I will attempt to tackle the scenarios - such as the Kaipeng and Juliet cases - with appeal to explicit changes in a single degree of belief. This is for clarity, and to narrow down the interpretative options. But bear in mind that the options are considerable in number when one thinks of the impact that a change in emotional state, say, might have on one's degrees of belief overall.

\section{Shifting Active Conditional Degrees of Belief}

The most common way for one's degrees of belief to shift is in response to changes in one's background information, or evidence (when 'evidence' is given a subjective spin). ${ }^{12}$ One far-fetched example, concerning Earth's impending doom, was presented above. But such shifting is commonplace, and typically much more mundane. As I write, for example, I am confident that no-one is standing outside my office. (Let $p$ be 'Someone is standing outside my office', and $b$ be my current background information; $\mathrm{D}_{\text {Author }}(p \mid b)<<0.5$.) But if I hear a knock on my door - or even hear a noise that I mistake for a knock on my door - then I will be confident that someone is outside my office. (Let $k$ be 'I just heard a knock on my office door';

\footnotetext{
${ }^{12}$ Here is one such subjective spin on evidence, for illustrative purposes: $e$ constitutes evidence for $h$ relative to $b$, for $\mathrm{S}$, when $\mathrm{D}_{\mathrm{S}}(h \mid e \& b)>\mathrm{D}_{\mathrm{S}}(h \mid b)$. (Note that 'relative to $b$ ' is important, because $e$ might not constitute evidence against $h$ in the absence of $b ; e$ and $b$ entail propositions that $e$ alone does not, for example.)
} 
$\mathrm{D}_{\text {Author }}(p \mid b \& k)>>0.5$.) In essence, such a shift involves a different conditional degree of belief becoming active.

Such shifts straightforwardly explain many cases in which actions might initially appear to be at odds with assertions. For example, Jack might sincerely declare to his wife, Jill, that he expects no rain on his hike tomorrow. But he might nevertheless pack waterproof gear the next morning. Jill might initially be surprised to see him pack the gear, and ask him to explain why he is doing so: "I thought you said you didn't expect rain?" However, she would not be surprised if Jack responded that he'd watched the news earlier in the morning, and discovered that the weather forecast had changed. Indeed, Jill's default position would be to expect Jack's degree of belief to have shifted. And after hearing his response, she would be entirely satisfied that his packing waterproof gear was consistent with his professed belief the night before.

This is uncontroversial. It is bordering on the trivial. But there are cases similar in kind where shifting of this form may be far less obvious. Imagine, for instance, that a subject's degree of belief in some proposition is only just over the threshold for it to count as a belief simpliciter, and thus as legitimately assertible. ${ }^{13}$ Think of a floating

\footnotetext{
${ }^{13}$ On the relationship between beliefs simpliciter and degrees of belief, and the role of thresholds, see Leitgeb (2013). A foray into the delicate issues surrounding the norm of assertion is unnecessary for present purposes. For example, we need not assume the rule of assertion criticized by Dudman (1992: 205), namely 'to assert what is highly probable'. It suffices to assume the following: (1) that it is necessary for $\mathrm{S}$ to believe that $p$ in order to legitimately assert (or, more precisely, asseverate) that $p$; and (2) that $\mathrm{S}$ only believes that $p$ when $\mathrm{S}$ 's active conditional degree of belief that $p$ is greater than some threshold value, $v$. Note that the proper (or rational) value for $v$ might alter by context, e.g. depending on whether only epistemic concerns are relevant. Similarly, the actual value for $v$ may alter
} 
voter (S), who declares that she intends to vote for one presidential candidate, Bill, rather than another $(p)$. Or consider a priest undergoing a crisis of doubt $(\mathrm{S})$, who nevertheless professes that God exists $(p)$. In each case, at the moment of assertion, the subject has a high enough degree of belief to count as believing what they assert, but only just. Let $v$ be the threshold for a degree of belief to count as a belief simpliciter; the context is such that (1) $\mathrm{D}_{\mathrm{s}}(p \mid b)>v$, although (2) $\mathrm{D}_{\mathrm{s}}(p \mid b) \approx v$. In such a situation, S's belief (simpliciter) in $p$ is highly unstable. In particular, almost any new (subjective) evidence against $p$ (in the presence of $b$ ) will change S's active degree of belief in $p$ such that it is under $v$, i.e., such that $\mathrm{S}$ no longer believes $p$. Let $e$ represent such new evidence against $p$. For the floating voter, this might be that Bill once 'smoked' a joint (but did not inhale). For the doubting priest, this might be learning of a terrible natural disaster, which has resulted in hundreds of deaths. The crucial point is that $\mathrm{D}_{\mathrm{s}}(p \mid b \& e)<v$, although $\mathrm{D}_{\mathrm{s}}(p \mid b)>v$, and that this may be extremely difficult for observers of $\mathrm{S}$ to realise unless they are aware not only that $\mathrm{D}_{\mathrm{s}}(p \mid b) \approx v$, but also that $e$ constitutes evidence against $p$ (in the presence of $b$ ) for $\mathrm{S}$.

The shifts described above might be rational. (That is to say, if the details are filled in appropriately. For the floating voter, for example, $b$ might contain the propositions 'Drug use is evil!' and 'Evil presidents are bad presidents!') But irrational shifts are possible too. A subject's degrees of belief may change in such a way that she becomes susceptible to being Dutch Booked, e.g. because she more strongly believes 
in $p$ than in $q$ although $q$ is entailed by $p .{ }^{14}$ Or what $\mathrm{S}$ counts as evidence, i.e. S's subjective evidence, may fail to be objective evidence. For example, a religious academic might take his promotion to full professor $(e)$ to be evidence that God exists (h) when it is no such thing (given the objective logical relations between $e, h$, and his background information, $b)$. Perhaps, for instance, $\mathrm{P}(h \mid e \& b)=\mathrm{P}(h \mid b)$ when the operant interpretation of probability is logical or objective Bayesian.

Now consider how the case of Kaipeng might involve irrational shifting of this form. ${ }^{15}$ Let $p$ be 'Death is bad!', $q$ be 'I am currently on the battlefield', $r$ be 'Death is imminent', and $s$ be $q \rightarrow r$. (For notational convenience, in what follows, we will 'sink' any other propositions in Kaipeng's background knowledge, $b$, into the D-function.) Now let's imagine that $\mathrm{D}_{\text {Kaipeng }}(p \mid r)=0.9$, whereas $\mathrm{D}_{\text {Kaipeng }}(p \mid \sim r)=0.1$. He finds himself on the battlefield. He accepts $s$ (as part of his background knowledge). So he infers $r$; $\mathrm{D}_{\text {Kaipeng }}(r \mid s \& q)=1 .{ }^{16}$ And as a result, his active degree of belief in $p$ becomes $\mathrm{D}_{\text {Kaipeng }}(p \mid r)$. Now because Kaipeng has a disposition to tremble when he has a high degree of belief in $p$ and $r$ - and there is nothing to prevent him trembling - he begins

\footnotetext{
${ }^{14}$ Or she may have inconsistent beliefs. This is the way that Rowbottom (2007) describes the Roshini case of Schwitzgebel (2011: 77): 'Roshini teaches fourth grade... typically she says that a prime number is any positive integer that can be divided evenly only by 1 and itself... Still, Roshini knows that 1 is not a prime.'

${ }^{15}$ I believe the Kaipeng case is compatible with several shifting possibilities, rational and irrational, conditional or not. I will return to it yet again in the next sub-section.

${ }^{16}$ There is no need to assume that said degree of belief in $r$ is one, rather than simply high. I make this assumption to avoid unnecessary technicalities; but one could use Jeffrey conditionalisation, for example, instead.
} 
to tremble. The explanation is clear, even if the fact that $\mathrm{D}_{\text {Kaipeng }}(p \mid r)=0.9$ shows that Kaipeng is not an ideally rational agent.

This almost concludes the coverage of shifting active conditional degrees of belief, which might be instead referred to as information-based shifting. It is worth adding only that in all the hypothetical situations discussed, the subjects' state of information does appear to change. For example, Juliet will presumably believe 'I am now looking at a non-Caucasian' when some of her racist behaviour kicks in, just as Kaipeng will presumably believe 'Death is imminent!' when some of his death-averse behaviour occurs. And since inactive conditional beliefs are not luminous, as we saw in the previous section, each may misjudge these. For example. Kaipeng may wrongly anticipate that his degree of belief that 'Death is not bad' will not alter when he comes to believe 'Death is imminent!'

\section{Shifting Values of Conditional Degrees of Belief}

It is also possible for shifting to occur when changes in state of information do not. And one possible cause of such shifts in degrees of belief is changes in propositional attitudes other than beliefs, such as fears and desires. Consider the Kaipeng case one final time. (This is the last time! I come back to the case with good reason, however, namely to illustrate how open it is to different shifting explanations.) Kaipeng goes onto the battlefield. Initially, his degree of belief in 'Death is not bad!' ( $p$ ) remains unaltered in value (despite changes in his state of information occurring); $\mathrm{D}_{\text {Kaipeng }}(p \mid b)=\mathrm{D}_{\text {Kaipeng }}\left(p \mid b^{*}\right)$, where $b$ is Kaipeng's background information before going onto the battlefield and $b^{*}$ is his background information after going onto the 
battlefield. (As noted previously, there are almost certain to be some changes in state of information. For example, he is highly likely to acquire a new background belief 'I am on the battlefield now'.) Shortly after setting foot on the battlefield, however, Kaipeng starts to experience fear (and/or other reactions such as disgust), although not enough to make him tremble. This may or may not have death as its direct object; perhaps the noise, the smoke, and the stench are responsible. The fear alters the value of $\mathrm{D}_{\text {Kaipeng }}\left(p \mid b^{*}\right)$ directly. ${ }^{17}$ And being aware that death is now a salient possibility, Kaipeng now begins to fear death too. Kaipeng begins to tremble.

Perhaps this kind of explanation seems a little ad hoc in the case of Kaipeng, but there is another case discussed by Schwitzgebel (2001: 78) where it does not:

In certain moods and in certain contexts, Antonio feels quite sure that the universe is guided by a benevolent deity. In other moods and contexts, he finds himself inclined to think of talk about God as "a beautiful metaphor" or even, sometimes, "a crock of hooey"... At the birth of a child or the death of a friend, he feels certain God is involved; when the church gossip group has invaded his house, the idea of taking literally talk about the existence of a benevolent deity strikes him as foolish.

Does Antonio believe that God exists? A simple yes or no answer to this question would be misleading... [M]ost of the time... he is eating breakfast or

\footnotetext{
${ }^{17}$ Is such a change rational? On some broad views of rationality, it might be. On others, it is not. But suffice it to reiterate that the shifting view is compatible with the view that some such shifts are rational, whereas others are not, as well as the view that no such shifts are rational.
} 
mowing or writing code and not giving the matter any thought. At such moments he may be simultaneously disposed to marvel at the wonder of creation if a robin were to fly past and to embrace atheism if Madge were unexpectedly to drop by.

A reasonable way to understand what is happening, here, is as follows. Antonio's degree of belief in 'God exists' changes not as a direct result of his changing state of information, but instead as a result of his different moods. (Indeed, Schwitzgebel specifically mentions 'moods' in the example.) Let Antonio's background information, $b$, remain fixed. And let 'God exists' be $p$. Perhaps $\mathrm{D}_{\text {Antonio }}(p \mid b)$ varies depending on what he's feeling. For example, perhaps Antonio typically experiences wonder at a birth or when a robin flies past, is typically in a calm state when mowing or coding, and typically experiences irritation when Madge drops by. And maybe $\mathrm{D}_{\text {Antonio-in-wonder }}(p \mid b)>\mathrm{D}_{\text {Antonio-calm }}(p \mid b)>\mathrm{D}_{\text {Antonio-irritated }}(p \mid b)$. Indeed, it is possible that Antonio is a believer when in wonder, agnostic when calm, and a non-believer when irritated. So 'A simple yes or no answer' to the question 'Does Antonio believe that God exists?' would indeed be misleading, if this were taken to range over all possible emotional states. But there is no feature of the situation that cannot potentially be explained by an appropriate appeal to degrees of belief. The convention is plausibly to answer the question by giving the (estimated) calm state value. For example, I tend to think of calm states when considering the ('global') beliefs of friends and relatives who suffer from depression and (type two) bipolar disorder. But in doing so, I don't lose sight of the shifting that occurs. I am aware that one friend suffers from low selfesteem at some points and overinflated self-esteem at others (i.e., during depressive 
and hypomanic episodes respectively). But I take him/her to have a middling sense of self-esteem for most of the time.

It is worth adding that the two forms of shifting might occur in unison. That's to say, someone's degree of belief might shift due to a change of information and shift again due to a change of mood. Moreover, a change in degree of belief might trigger a change of mood, and vice versa. Consider a final example.

Marcus and Cleopatra met each other on an online dating site, and have corresponded regularly. They've exchanged numerous photos, talked about their lives, and even discussed their sexual fantasies. The day of their first date arrives. Marcus is highly confident that he's going to kiss Cleopatra on the date. And that's what he tells his best friend, Julius, before leaving their shared apartment. Upon meeting Juliet, however, his confidence is shaken. First, she looks rather different from how he expected her to look. So he isn't as smitten by her appearance as he expected to be, and isn't so confident that he wants to kiss her. (Thus, he isn't so confident that he will kiss her.) Second, moreover, he finds that he's nervous, although he doesn't understand why. (Maybe it's partly because of her unexpected appearance, but that isn't the only reason.) So he's not sure he has the guts to attempt to kiss her, or even to respond if she attempts to kiss him. And this further lowers his degree of confidence that he will kiss her. They don't kiss. The date ends. Marcus returns home, dejectedly. He calms down after a few hours, and starts looking at Cleopatra's photos again. He berates himself, in front of the mirror: "Why didn't you go for it, you idiot?" He goes online, and sets up another date for later in the week. He is again confident that he will kiss Cleopatra when they next meet. And he again declares that 
he will kiss her to his buddy, Julius. However, the truth is that he will again be struck by the difference between the real Cleopatra and his mental image of her, and again be nervous on the date. The kiss will never happen. Cleopatra will find this offputting. And there will be no more dates.

\section{Conclusion}

I have argued that the shifting view has been seriously underestimated, and too hastily dismissed, in the literature to date on mismatches between assertions and actions. For when attention is paid to the specific means by which shifting of degrees of belief might occur, it becomes evident that the shifting view has considerable explanatory resources. Since shifting certainly occurs some of the time, moreover, it is a neat result, in terms of simplicity, when cases involving mismatches between assertions and actions can be understood in these terms. ${ }^{18}$

The aim of this paper has been relatively modest, and the following question remains. Are there any reasons for thinking that the shifting belief view should be preferred, if only in a proper subset of the mismatch scenarios, to the available alternatives? If I

\footnotetext{
${ }^{18}$ As indicated elsewhere, e.g. Rowbottom (2011 \& 2015a \& Forthcoming), I defend an empiricist, anti-realist, view of science. I believe that we may reasonably choose between theories on the basis of supra-empirical theoretical virtues, such as simplicity, (external) consistency, and scope. However, I construe such virtues to be pragmatic, rather than epistemic, and I don't take them to have any context invariant priority ordering. However, realists are welcome to evaluate the shifting view I've outlined or parts thereof - on their own terms.
} 
were forced to answer in the affirmative, I'd point to scenarios involving major changes in a subject's background information or emotional state. ${ }^{19}$

\section{Acknowledgements}

My thanks to Eric Schwitzgebel and three anonymous referees for helpful feedback on previous versions of this paper.

\section{References}

Audi, R. N. 1994. 'Dispositional Beliefs and Dispositions to Believe', Nô̂s 28, 419434.

Borgoni, C. 2014. 'Dissonance and Irrationality: A Criticism of The In-Between Account of Dissonance Cases', Pacific Philosophical Quarterly.

Chandler, J. 2014. 'Subjective Probabilities Need Not Be Sharp', Erkenntnis 79, $1273-1286$.

Cummins, R. 1996. Representations, Targets, and Attitudes. Cambridge, MA: MIT Press.

\footnotetext{
19 'Major' is vaguer than I should like, and especially difficult to specify in the case of background information. But I take there to be some uncontroversial examples of significant changes. Consider (typical) emotional states on the battlefield versus (typical) emotional states when reading and reflecting, which are pertinent to the Kaipeng case.
} 
Cushing, J. T. 1994. Quantum Mechanics: Historical Contingency and the Copenhagen Hegemony. Chicago: University of Chicago Press.

De Finetti, B. 1937. 'Foresight, its Logical Laws, its Subjective Sources', in H. E. Kyburg and H. E. Smokler (eds), Studies in Subjective Probability. New York: Wiley, pp. 93-158.

De Finetti, B. 1990. Theory of Probability, Vol. I. New York: Wiley.

Dudman, V. H. 1992. 'Probability and Assertion', Analysis 52, 204-211.

Erikkson, L. and Hájek, A. 2007. 'What Are Degrees of Belief?', Studia Logica 86, $183-213$.

Fodor, J. 1975. The Language of Thought. Cambridge, MA: Harvard University Press.

Gendler, T. S. 2008a. 'Alief and Belief', Journal of Philosophy 105, 634-663.

Gendler, T. S. 2008b. 'Alief in Action (and Reaction)', Mind and Language 23, 552585.

Gertler, B. 2011. 'Self-Knowledge and the Transparency of Belief', in A. Hatzimoysis (Ed.), Self-Knowledge. Oxford: Oxford University Press. 
Gillies, D. 2000. Philosophical Theories of Probability. London: Routledge.

Hutto, D. D. 2013. 'Why Believe in Contentless Beliefs?', in N. Nottelmann (ed.), New Essays on Belief, London: Palgrave Macmillan, 55-74.

Joyce, J. M. 2010. 'A Defense of Imprecise Credences in Inference and Decision Making', Philosophical Perspectives 24, 281-323.

Keynes, J. M. 1921. A Treatise on Probability. London: Macmillan.

Leitgeb, H. 2013. 'Reducing Belief Simpliciter to Degrees of Belief', Annals of Pure and Applied Logic 164, 1338-1389.

Ramsey, F. P. 1926. 'Truth and Probability', in H. E. Kyburg and H. E. Smoklet (Eds), Studies in Subjective Probability. New York: Wiley, pp. 63-92.

Rowbottom, D. P. 2007. “"In-Between Believing” and Degrees of Belief', Teorema $26,131-137$.

Rowbottom, D. P. 2011. 'The Instrumentalist's New Clothes', Philosophy of Science $78,1200-1211$.

Rowbottom, D. P. 2015a. 'Scientific Progress Without Increasing Verisimilitude: In Response to Niiniluoto', Studies in History and Philosophy of Science 51, 100-104. 
Rowbottom, D. P. 2015b. Probability. Cambridge: Polity Press.

Rowbottom, D. P. Forthcoming. 'Extending the Argument from Unconceived Alternatives: Observations, Models, Predictions, Explanations, Methods, Instruments, and Values', Synthese.

Schwitzgebel, E. 2001. 'In-Between Believing', Philosophical Quarterly 51, 76-82.

Schwitzgebel, E. 2002. 'A Phenomenal, Dispositional Account of Belief', Nous 36, $249-275$.

Schwitzgebel, E. 2008. 'The Unreliability of Naïve Introspection', Philosophical Review 117, 245-273.

Schwitzgebel, E. 2010. 'Acting Contrary to Our Professed Beliefs, or the Gulf Between Occurrent Judgment and Dispositional Belief', Pacific Philosophical Quarterly 91, 531-553.

Schwitzgebel, E. 2011. 'Knowing Your Own Beliefs', Canadian Journal of Philosophy 35 (supplementary), 41-62.

Williamson, J. 2010. In Defence of Objective Bayesianism. Oxford: Oxford University Press. 
Preprint - Forthcoming in Philosophical Psychology

Williamson, J. 2015. 'Deliberation, Judgement and the Nature of Evidence', Economics and Philosophy 31, 27-65.

Zimmerman, A. 2008. 'The Nature of Belief', Journal of Consciousness Studies 14, 61-82. 